\title{
Levando o cérebro para além do campus: criando laços entre a Universidade e a comunidade para divulgaçáo científica
}

Taking the brain beyond the university: building links between the University and the community for scientific disclosure

\section{RESUMO}

A compreensão de aspectos gerais acerca da organização e do funcionamento do sistema nervoso é importante, uma vez que traz diversos benefícios para uma melhoria na qualidade de vida da população em geral. Este texto tem a finalidade de relatar a organização e o impacto de um conjunto de açôes de divulgaçáo neurocientífica realizadas junto à comunidade de Uruguaiana, Rio Grande do Sul. Ao longo do ano de 2016, a equipe do programa de extensão POPNEURO participou de eventos e feiras que ocorreram em diferentes locais do município, promovidos por escolas e associaçóes, proporcionando atividades de popularização da neurociência para o público em geral, e, assim, criando laços entre a Universidade e a comunidade. Dentre as temáticas tratadas estão: neuroanatomia e neurofisiologia, doenças do cérebro, microcefalia e neuromitos. Lançamos mão de diversas estratégias, dentre as quais se destacam o uso de peças anatômicas sintéticas, cartazes e fôlderes autoexplicativos. Percebemos a ativa participaçáo de uma populaçáo de diversas faixas etárias, com níveis de interesse variados de acordo com a temática. As atividades propostas atenderam o objetivo de popularizar conceitos importantes da neurociência, de forma agradável e lúdica, além de permitir a interação entre a comunidade e Universidade.

Palavras-chave: Neurociência. Divulgação científica. UniversidadeComunidade. Popularização da ciência.

\section{ABSTRACT}

The understanding of general aspects of the Nervous System organization and its functioning is very important, since it brings several benefits to an improvement in the quality of life of the population in general. The objective of this study is to report the organization and the impact of a set of neuroscientific dissemination actions in the community of Uruguaiana, State of Rio Grande do Sul,
Andressa Ferreira Mandarino

Graduanda em Fisioterapia na Universidade Federal do Pampa, Campus Uruguaiana, Rio Grande do Sul, Brasil; bolsista de extensáo do Programa "POPNEURO: açōes para divulgaçáo e popularização da Neurociência”. (emmandarino@hotmail.com).

Liane da Silva de Vargas

Doutoranda em Ciências Biológicas (Fisiologia) na Universidade Federal do Rio Grande do Sul, Brasil; professora colaboradora no curso de Especialização em Neurociência Aplicada à Educação da Universidade Federal do Pampa, Rio Grande do Sul, Brasil; membro do Grupo de Pesquisa em Fisiologia. (lianeevargas@ gmail.com).

Pâmela Billig Mello-Carpes

Pós-doutora em Neurofisiologia pela Katholieke Universiteit Leuven, KU Leuven, Bélgica; professora na Universidade Federal do Pampa, Rio Grande do Sul, Brasil; líder do Grupo de Pesquisa em Fisiologia e coordenadora do Programa "POPNEURO: açóes para divulgação e popularizaçáo da Neurociência”.(pamelacarpes@ unipampa.edu.br). 
Brazil. Throughout the year 2016, the team of the outreach program POPNEURO participated in many events and fairs that took place in different places of the city and were promoted by schools and associations, promoting neuroscience dissemination activities to the public, and creating links between the university and the community. The themes that were explained at the events were neuroanatomy and neurophysiology, brain diseases, microcephaly and neuromyths. We elaborated a set of strategies to approach these themes: the use of synthetic anatomical pieces, posters and folders. During the actions we noticed the active participation of people of different age groups with different levels of interest according to the theme. The activities proposed by the group met the objective of popularizing important concepts of neuroscience in a pleasant and ludic way, besides allowing interaction between the community and the university.

Keywords: Neuroscience. Scientific dissemination. UniversityCommunity. Science popularization.

\section{INTRODUÇÃO}

A paixão pela descoberta é natural a todos. As pessoas costumam buscar por respostas, procuram entender as coisas que as cercam. É como se cada um de nós fosse um pouco cientista e, sendo assim, cada indivíduo possui um pouco do conhecimento científico como algo totalmente comum, mesmo que intrinsecamente (VARGAS et al., 2013). Dessa forma, é importante que a produção científica e sua divulgaçáo não sejam restritas apenas a cientistas, mas que sejam levadas, de alguma maneira, ao público em geral. Uma iniciativa que tem contribuído para isso é a divulgação e popularização da ciência para a comunidade. A ciência relacionada ao cérebro, Neurociência, vem ganhando um destaque nesse cenário, uma vez que seus estudos trazem diversos benefícios para a melhoria na qualidade de vida da população em geral.

A Neurociência é o ramo da ciência que estuda o sistema nervoso (SN), suas estruturas e funcionamento (FILIPIN et al., 2015). Os conhecimentos acerca do cérebro oferecem uma série de incentivos para melhorar a qualidade de vida das pessoas, entretanto, com 
o avanço nas pesquisas e descobertas nessa área, também há um aumento da disseminação de informaçóes a este respeito, propensas, frequentemente, a equívocos o que contribui para a propagaçáo de conceitos errôneos, ou ainda, muitas vezes, essas informações nem chegam ao público leigo (ILLES et al., 2010; DEKKER et al., 2012). Desse modo, é importante que as descobertas e novidades do mundo científico não fiquem restritas a revistas especializadas, devendo ser levadas ao público geral, porém com muita responsabilidade (VARGAS et al., 2013).

Nesse sentido, Hernando (2005, p. 18) acredita que a divulgação científica é um dos maiores desafios deste século e afirma que "se queremos realmente uma sociedade democrática, é preciso que todos entendam a ciência”, e que o engajamento com o público é uma responsabilidade. Entretanto, para isso, os cientistas devem sair de seus campi, laboratórios e instituiçóes e ir para as comunidades a fim de se envolverem em um diálogo ativo com seus concidadãos (FRIEDMAN, 2008). Porém, conduzir esses conceitos para a prática é o que se torna realmente dificultoso, principalmente devido à falta de motivação e ao fraco investimento na divulgação científica.

Com o objetivo de melhorar as relações entre ciência e mídia, diversas estratégias já foram implementadas, entre elas, a criação de workshops de formaçáo para preparar os cientistas para o contato com a comunidade (PETERS, 2008). Apesar da obtenção de bons resultados acerca da satisfação e da interação entre ambos, existem fatores que ainda despertam a falta de interesse dos cientistas em participar do compromisso com o público, sendo o principal o pouco reconhecimento acadêmico dado a esse tipo de ação e sistemas de mérito que oferecem pouco ou nenhum crédito para os esforços de divulgaçáo da ciência ao público, tais como escrever livros para os leigos e/ou dar entrevistas na mídia ou palestras públicas.

Segundo Poliakoff e Webb (2007), os esforços para popularizar a ciência podem, às vezes, estigmatizar um pesquisador e até mesmo comprometer a credibilidade profissional, sendo possível sentir que o seu trabalho de divulgação e mídia não será considerada uma realização comparável a uma publicação científica. $\mathrm{O}$ próprio cientista deixou de ser a única opção a se considerar quando o assunto é se ocupar 
da divulgação científica. O perfil ideal do divulgador da ciência tem sido tema de discussão, uma vez que passou a ser defendido que não é necessário ser um profissional para atuar e sim que qualquer educador ou educando é capaz de contribuir na disseminação da ciência (MARANDINO, 2004), desde que o faça com responsabilidade.

Diante do exposto, este texto busca relatar uma série de atividades de divulgação e popularização da Neurociência realizadas por um grupo de estudantes de diversos cursos da Universidade Federal do Pampa (UNIPAMPA), campus Uruguaiana, sob supervisão docente, em eventos destinados à comunidade em geral fora dos muros dessa instituição, com o objetivo de popularizar conceitos científicos sobre o cérebro e o sistema nervoso de uma maneira agradável e lúdica, criando laços entre a Universidade e a comunidade a partir da aproximaçáo dos participantes com a Neurociência.

\section{METODOLOGIA}

As atividades descritas neste relato constituíram algumas dentre as diversas açóes extensionistas propostas pelo programa multidisciplinar POPNEURO. O Programa visa à divulgação e popularização de conceitos importantes da Neurociência ao público em geral, a partir da participaçáo em eventos públicos, no estilo de feiras de ciência, fora da UNIPAMPA, realizados ao longo do ano de 2016. Nessa perspectiva, o grupo foi convidado a participar de um grande número de eventos, exposiçóes e feiras promovidos pelas entidades de bairro e instituições de ensino de Uruguaiana, Rio Grande do Sul. Tais convites partiram do conhecimento das atividades de divulgação da Neurociência propostas pelo POPNEURO já previamente realizadas no município e região, já que o programa existe desde 2013.

Para realização das açóes, foi firmado um acordo entre o programa de açóes extensionistas e a instituiçáo ou entidade que estava a promover o evento. No ano de 2016, foram realizados esses tipos de açóes em duas escolas da rede pública do município (Figura 1), e uma entidade 
de bairro e uma associação (Figura 2). Os responsáveis por esses locais procuraram os integrantes do POPNEURO com a finalidade de proporcionar à comunidade açóes informativas e atividades de divulgação e popularização da Neurociência, além de incentivar uma aproximaçáo dos acadêmicos da UNIPAMPA com o público em geral.

Figura 1 - Ações de divulgação da Neurociência aos estudantes e a toda comunidade escolar de duas instituições de ensino públicas do município. A) Evento de divulgação científica em uma escola do município de Uruguaiana/RS. Integrantes do POPNEURO fazendo breves explanações sobre neurociência para o público infanto-juvenil e sanando suas dúvidas. B) Feira de Ciências em uma escola, em que a equipe do POPNEURO foi convidada a participar levando suas atividades de divulgação da Neurociência e exposição de peças anatômicas.

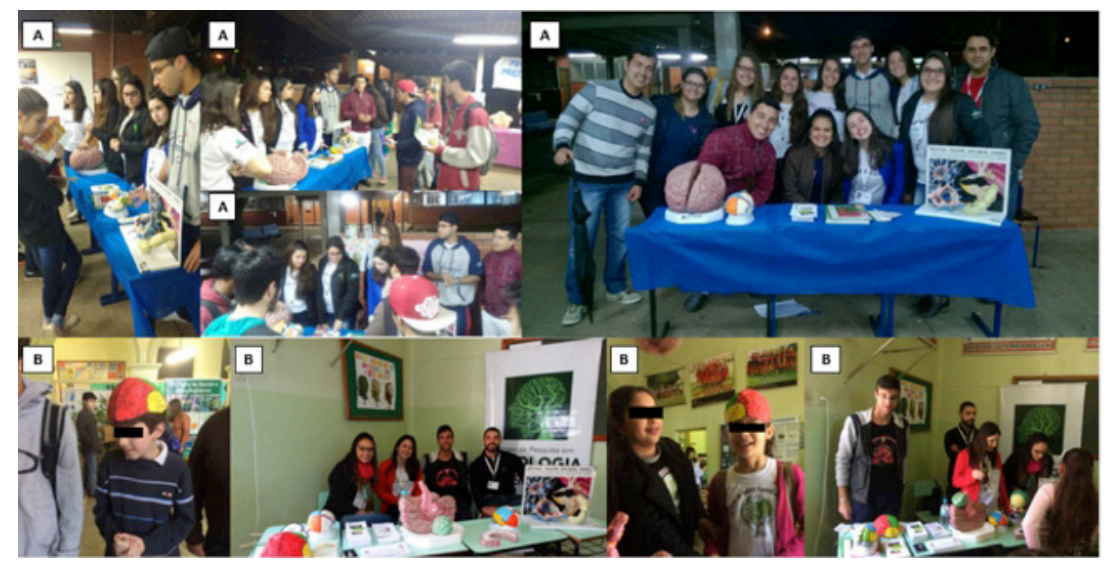

Fonte: POPNEURO (2016). 
Figura 2 - Ações de popularização neurocientífica extraescolares. A) Evento promovido pela Associação Rural de Uruguaiana-RS. Integrantes do POPNEURO interagindo com público de diversas faixas etárias, com atividades recreativas para todas as idades. B) Acadêmicas do POPNEURO durante a Ação Cívica Social (ACISO 2016) promovida no bairro Mascarenhas de Moraes, Uruguaiana-RS.

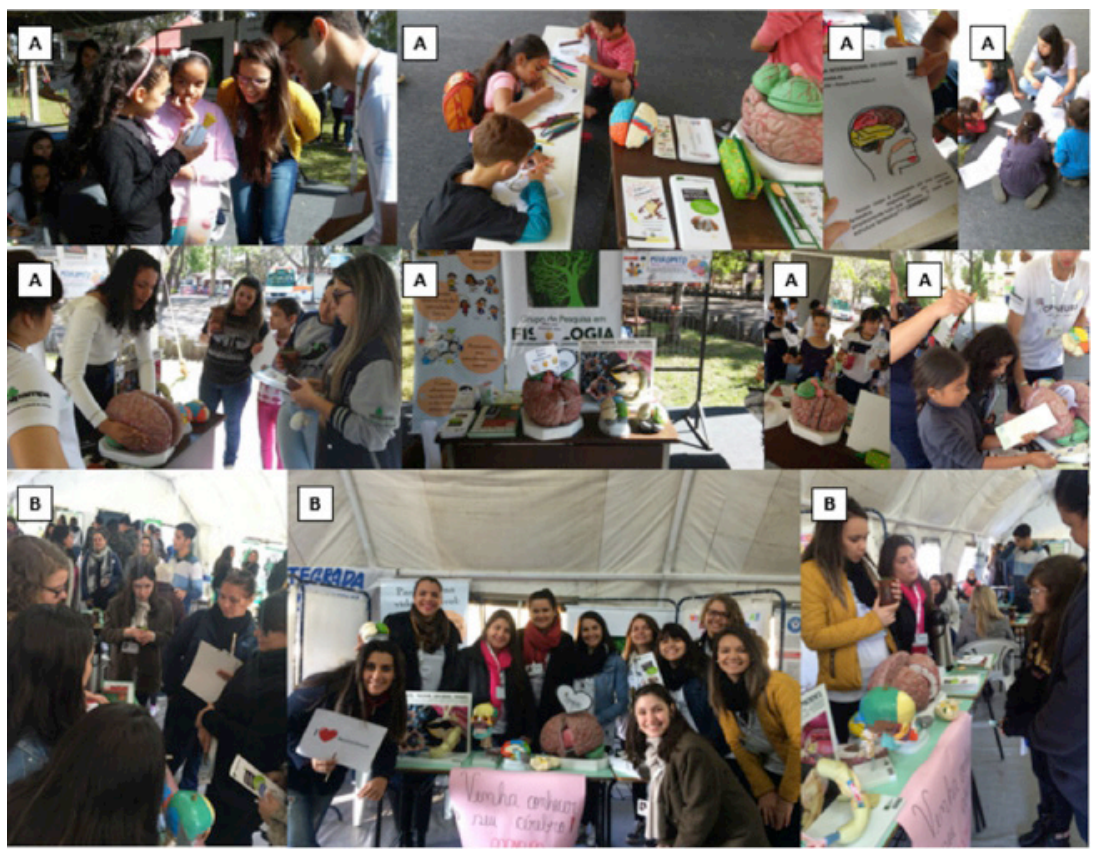

Fonte: POPNEURO (2016).

Previamente aos eventos, a equipe envolvida, constituída por três docentes doutores (sendo um coordenador), uma doutoranda e 23 alunos de graduação dos cursos de Educação Física, Enfermagem, Farmácia e Fisioterapia da UNIPAMPA, fez o planejamento e a organização de quais temáticas seriam levadas ao público, considerando seus interesses. Definidos os temas e planejadas as atividades a serem realizadas, procedemos ao treinamento necessário para a realização adequada dessas atividades e o uso de linguagem apropriada para transmitir as informaçóes ao público. Desse modo, foram organizadas explanaçôes simples e diversas atividades práticas abertas a todos.

Para abordagem dos temas, lançamos mão de diversas estratégias, dentre as quais se destacam: o uso de peças anatômicas sintéticas; a entrega de fôlderes autoexplicativos; o uso de cartazes, contendo 
figuras e informações; e um "mini varal”, estampando capas de revistas que abordavam assuntos relacionados à Neurociência de forma midiática e equivocada, gerando neuromitos ${ }^{1}$, entre outros. Dentre as temáticas propostas nos eventos, e as respectivas atividades propostas para trabalhá-las, estão:

a. Neuroanatomia e neurofisiologia: a fim de divulgar o sistema nervoso, suas estruturas e funcionamento, foi considerada a necessidade de abordar uma introdução ao tema, contendo uma explanação teórica curta que incluíssem os aspectos mais específicos da anatomia do cérebro e sistema nervoso, a partir da utilização de peças anatômicas (Figura 3-A). Foi evidenciado ao público, pelos membros da equipe, que o sistema nervoso não consiste apenas do cérebro, mas sim de diversas outras estruturas, como o tronco encefálico, cerebelo, medula espinhal e nervos. Também foi destacado que o cérebro não possui somente as divisóes de hemisfério direito e esquerdo, mas é anatômico e funcionalmente organizado em lobos. Para as crianças também foram disponibilizadas figuras com o desenho do cérebro para colorirem.

b. Doenças do cérebro: para trabalhar tal temática, partimos da entrega de fôlderes autoexplicativos (Figura 3-B), contendo informações acerca das doenças mais comuns e conhecidas que afetam o cérebro: Acidente Vascular Encefálico (AVE), incluindo as diferenças de isquêmico (isquemia cerebral) para hemorrágico (popularmente conhecido como derrame); Parkinson e Alzheimer. A temática procurou sanar dúvidas a respeito dessas doenças populares na comunidade e fazer uma relação com a fisiopatologia do sistema nervoso por meio da peça anatômica do cérebro com os vasos sanguíneos destacados (Figura 3-C), mostrando que, no AVE isquêmico, ocorre interrupção do fluxo sanguíneo dos vasos que levam sangue ao encéfalo, enquanto que, no AVE hemorrágico, há um rompimento desses vasos, provocando sangramento.

c. Microcefalia: esse tema foi incluído em uma ação específica, considerando a grande quantidade de casos de infecção pelo Zika Vírus e, consequentemente, microcefalia, relatados no Brasil entre 2015 e 2016. Para iniciar a abordagem do tema
${ }^{1}$ Um neuromito pode ser caracterizado como uma informaçáo equivocada a respeito de conceitos relacionados ao Sistema Nervoso (SN) disseminada à populaçăo em geral (BUENO; EKUNI; ZEGGIO, 2015). Um neuromito pode surgir de várias formas, como por exemplo, em uma leitura errônea ou uma má interpretação dos dados científicos, ou também por informaçōes infundadas amplamente divulgadas pela mídia (DEKKER et al., 2012). O que geralmente acontece é que a população em geral, que náo tem acesso ou náo tem um conhecimento prévio acerca do funcionamento do $\mathrm{SN}$, acaba acreditando e replicando essas falsas informaçōes (BUENO; EKUNI; ZEGGIO, 2015) 
foram entregues calendários (Figura 3-D) com informaçôes sobre o assunto que estava sendo amplamente tratado na mídia. Explanações detalhadas sobre essa condição neurológica rara que causa uma má formação do sistema nervoso central, seus sintomas, prevençôes e o entendimento da relaçáo entre microcefalia e zika vírus foram dadas pelos membros da equipe aos participantes.

d. Neuromitos: neste tópico, procuramos promover a desmistificaçáo de alguns dos neuromitos mais comuns a partir da utilização de cartazes coloridos com informaçóes sobre o assunto e de como esses mitos se formam (sua origem) e são disseminados. Também confeccionamos um "mini varal" com capas de revistas brasileiras conhecidas (reais), em que se verificavam exemplos da propagaçáo de neuromitos (Figura 3-E). Os neuromitos abordados incluíram: "Pílula da inteligência: ela existe?", "Aprendemos somente na infância", "Usamos somente $10 \%$ da capacidade do cérebro" e "Teoria localizacionista das funçôes cerebrais". Durante a desmistificação dos mitos, os membros da equipe iam retirando as capas das revistas populares do varal, em uma atitude simbólica para que o público entendesse que aquelas informaçóes não passavam de mitos. 
Figura 3 - Materiais propostos para a abordagem das temáticas durante as ações de divulgação da neurociência. A) Peças anatômicas sintéticas de estruturas importantes do sistema nervoso. $\mathrm{Na}$ imagem, modelos de cérebro humano do tamanho, sendo um no crânio e um modelo de neurônio e seus principais componentes. Além de visualizar, os participantes ofereciam ao público a oportunidade de pegar e manusear as peças com a finalidade de um melhor entendimento do assunto. B) Fôlderes autoexplicativos confeccionados pela equipe do POPNEURO com diversas informações sobre AVE isquêmico e hemorrágico, Parkinson e Alzheimer. C) Peça anatômica ilustrativa do cérebro, tronco encefálico e cerebelo (tamanho maior que o natural, para melhor visualização), por meio da qual foram mostrados os vasos sanguíneos presentes nessas estruturas e a relação com situações patológicas. D) Calendário do ano de 2016 com esclarecimentos a respeito da microcefalia, ressaltando tópicos como "O que é?”; "O que pode levar a microcefalia?”; "Quais os problemas causados pela microcefalia?” e medidas de prevenção. E) Cartazes elaborados por membros da equipe do POPNEURO e impressão de capas de revistas com manchetes de algumas ideias oriundas de dados neurocientíficos, mas que não passam de especulações ou má interpretação (neuromitos).

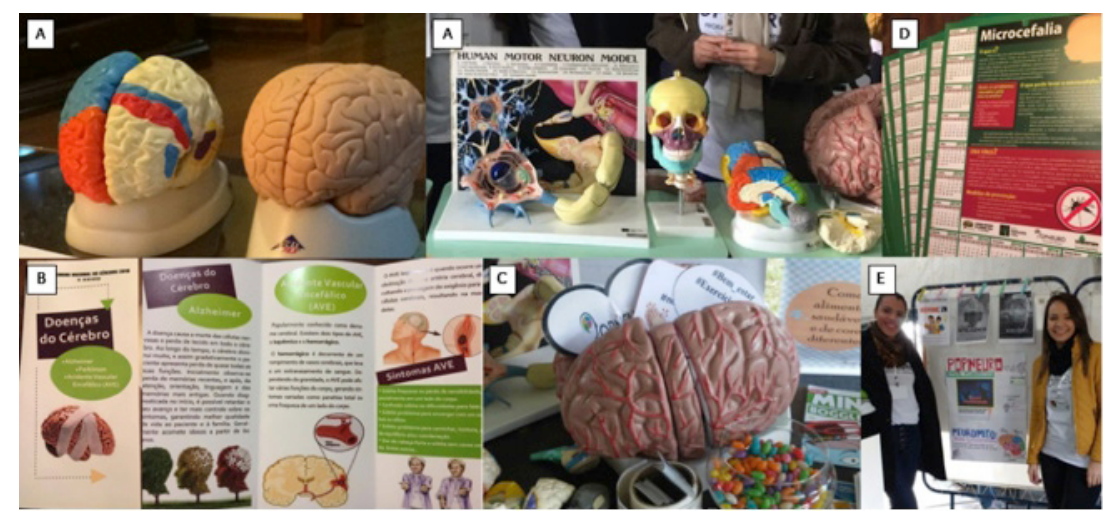

Fonte: POPNEURO (2016).

Em todas as abordagens os estudantes de graduação membros da equipe forneciam explicaçóes dialogadas relacionadas às temáticas trabalhadas. 


\section{RESULTADOS}

Nas diversas açóes realizadas, percebemos que a recepção, tanto nas instituiçóes de ensino, quanto nos eventos de bairro, foi bastante atenciosa, tornando o ambiente agradável para a organização dos materiais e a prática das atividades. Embora os temas, a criação e o planejamento das atividades para as diversas ações tenham sido similares, a forma com que o público lidou e interagiu com os diversos assuntos foi diferente conforme o local e a ocasião. Isto não gerou problemas, pois as atividades foram planejadas para envolver um grande e diversificado público, considerando o objetivo da proposta. Foram propostas práticas simples, com linguagem clara e adequada, baseando-se na escuta das dúvidas do público-alvo e no diálogo ativo entre os integrantes e o público. Assim, houve questionamentos, relatos e trocas de experiências, o que permitiu uma aproximaçáo da Universidade com a comunidade à qual ela está inserida.

Observou-se que, nas açóes de divulgação realizadas em feiras nas escolas, houve um maior número de jovens como público-alvo, que demonstraram interesse em uma ou mais temáticas propostas para a ação. Esse público relatou já possuir algum conhecimento prévio sobre o funcionamento do cérebro (fruto de disciplinas escolares, como a Biologia), e trouxe novas e diferentes perguntas durante as atividades. Já nas atividades realizadas nos bairros e eventos de associaçóes houve a participação de pessoas de diferentes faixas etárias, incluindo crianças, jovens, adultos e idosos, e todos consideraram as atividades de extrema relevância, visto que elas lhes permitiram acrescentar novos conhecimentos a respeito do sistema nervoso e suas funçóes. Esse segundo público, mais heterogêneo, em sua maioria não possuía nenhum conhecimento prévio a respeito dos assuntos abordados, mas, por intermédio das explicaçóes da equipe tornou-se capaz de reforçar ou promover conhecimentos sobre as estruturas, importância e funcionamento do Sistema Nervoso Central (SNC). Acreditamos que isso permitirá que as pessoas adotem práticas mais condizentes com a saúde dos órgãos que compóem o SN.

Considerando as quatro ações de divulgação e popularização da Neurociência, nas quais a equipe se envolveu em 2016, totalizamos a participaçáo de aproximadamente 1000 pessoas. Houve um grande envolvimento das crianças com as peças anatômicas e curiosidade 
a respeito delas. Ainda, houve momentos de debates entre os participantes a respeito das temáticas abordadas, o que possibilitou a troca de conhecimentos e esclarecimentos sobre as doenças do cérebro e microcefalia, e neuromitos, sendo esta última uma das temáticas que atingiu um maior público, pois gerou muita curiosidade. Verificamos que a população ainda é propensa à distorção de fatos científicos envolvendo o cérebro.

Por fim, as informaçóes e as temáticas propostas geraram grande interesse da população, mostrando-se relevantes e de fácil entendimento. As explanaçóes simples e o uso de cartazes e entrega de fôlderes funcionaram como uma boa ferramenta, e permitiram sanar as dúvidas e curiosidades de muitos sobre questôes simples, como por exemplo, os benefícios da prática de exercícios físicos para ajudar a prevenir doenças do cérebro e as formas de prevenção da microcefalia. Assim, podemos afirmar que as açôes atingiram seus objetivos, uma vez que o público demonstrou grande interesse pelas temáticas, gerando a popularizaçáo da Neurociência por meio das explicaçôes dialogadas propostas.

A avaliação direta do público acerca das atividades realizadas não foi possível de ser realizada. Apesar da expectativa da equipe, que havia elaborado um questionário, o grande fluxo de pessoas nos eventos, que tiveram características de "feira científica ou de saúde", impossibilitou que controlássemos essa coleta, de forma que poucas pessoas responderam ao questionário. A maioria participava entusiasmadamente das atividades propostas, e, logo após, seguia para realizar outras atividades que ocorriam no evento, enquanto a equipe já estava envolvida com o atendimento de novo público.

\section{DISCUSSÃO}

São notáveis as vantagens encontradas a partir do estreitamento dos laços entre a UNIPAMPA e a comunidade na qual ela está inserida. Tais vantagens se estendem bilateralmente, uma vez que os discentes da instituição são capazes de transmitir o conhecimento acadêmico para os membros de seu município, e levar seus projetos de pesquisa, ensino e extensão para dentro das comunidades, aprendendo também com elas. Embora a inserção dos acadêmicos no meio comunitário 
apresente-se ainda inexpressiva e escassa (GIL; OLIVA; GASPAR, 2008), é importante ressaltar a necessidade da construção de uma sociedade em que as classes populares deixem de ser atores subalternos e explorados, tornando-se sujeitos ativos e importantes na definição de seus conhecimentos e diretrizes culturais (VASCONCELOS; 2004).

A UNIPAMPA, desde sua fundação em 2006, contribuiu significativamente para o crescimento do município de UruguaianaRS, assim como para o desenvolvimento cultural, social e econômico da regiáo, e recentemente, com a graduaçáo de seus alunos do campus Uruguaiana nas áreas de saúde, também tem contribuído para melhorar o segmento da saúde. Rykun et al. (2015) ressaltam que as universidades atuam como um dos fatores de influência mais significativos para o desenvolvimento da economia regional, dado que os locais em que elas estão estabelecidas são supostamente os lugares onde novas ideias são criadas, o que, eventualmente, resulta na criação de novos produtos ou serviços. Assim, como ocorre nas comunidades de Uruguaiana-RS, esta relação estabelecida com a universidade gera novas ferramentas, linguagens, histórias, e a construção do conhecimento social, muito mais que o mero compartilhamento de informaçôes. Neste contexto, Hackney (1986) já afirmava que um dos principais objetivos do desenvolvimento de sistemas de ensino superior é contribuir cada vez mais para a evoluçáo das comunidades locais, das cidades e das regióes. Em contrapartida, Borges (2005) lança mão da dificuldade encontrada pelas universidades brasileiras em se envolver com os processos sociais, econômicos e culturais, portando-se como uma entidade independente e demonstrando sua falta de compromisso com a sociedade; assim, a Universidade ainda parece estar longe de ser uma instituição social que possui a responsabilidade de se manifestar e comportar a partir de um espelho do modo de funcionamento da sociedade como um todo.

A fim de reafirmar esse compromisso com a sociedade, o campus Uruguaiana da UNIPAMPA tem implementado a política de projetos de extensão, que prevê como estratégia uma aproximação da Instituição com a sociedade em geral (MARCHIORO et al., 2007). Esses projetos, em diferentes áreas, tem ao menos um resultado em comum, que é a divulgação da universidade, considerado que há poucos anos grande parcela da população local desconhecia o funcionamento da universidade pública, seus objetivos e até mesmo 
o fato de ela oferecer ensino superior gratuito (MARTINS; MELLOCARPES, 2014). Com a ampliação dessas atividades, fortaleceu-se ainda mais a noção de que a universidade pode contribuir com a região (HOFF; SAN MARTIN; SOPEÑA, 2011).

O POPNEURO - Programa de Divulgação e Popularização da Neurociência, sendo um programa de extensão da UNIPAMPA, promove o contato da comunidade universitária com a sociedade, proporcionando ao universitário uma formação extensionista, com ênfase em habilidades de divulgação e comunicação científica. Jezine (2004) destaca a concepção de extensão como função acadêmica da universidade, revelando um novo objetivo no pensar e fazer, em que se estimula uma postura de organização e intervenção na realidade, na qual a comunidade deixa de ser passiva no recebimento das informaçóes/conhecimentos transmitidos pela universidade e passa a ser participativa, construtora e crítica dos possíveis modos de organização e cidadania. Thiollent (2002), por sua vez, cita a extensão como um processo contínuo de produção de conhecimentos, que abrange além dos acadêmicos, atores e públicos com culturas, interesses e níveis de educação diferenciados, promovendo, assim, um diálogo ativo com indivíduos que possuem diferentes experiências e escolaridades, assim como aconteceu nas açóes do POPNEURO.

Durante as atividades, os acadêmicos foram capazes de notar a preferência e interesse de alguns participantes por determinadas temáticas; temáticas estas que estavam relacionadas à suas histórias e experiências de vida. Adultos e idosos, por exemplo, procuraram saber a respeito das doenças do cérebro, o que pode acarretar na prevenção de doenças e seus sintomas. Já o público infanto-juvenil procurou sanar dúvidas relacionadas a informaçóes advindas de filmes ou da mídia, principalmente Internet, por meio de diálogos com os integrantes da equipe, questionando sobre se os fatos divulgados eram verdadeiros ou se não passavam de mitos acerca do cérebro. Pasquinelli (2012) afirma que os neuromitos existem por diversos fatores, tais como a desinformação, a má interpretação, e a ansiedade da população em saber informaçôes sobre o cérebro, fazendo com que ela acredite em tudo que lê, sem buscar, necessariamente, uma fonte de veracidade. Açóes como essa permitem um momento de reflexão acerca das informaçôes divulgadas pela grande mídia, e, se for o caso, a elucidação de mitos científicos. Nascimento Júnior e 
Souza (2009) confirmam que, durante a ação conjunta, há troca de vivências, socialização, questionamentos, reflexão e possibilidade de avaliação dos conhecimentos.

Assim, considerando as diferentes realidades locais, percebe-se que a popularização da ciência só será possível se a difusão de informações científicas passar por um processo de decodificação ou recodificação do discurso especializado para chegar ao público leigo, com a utilização de recursos como metáforas ou ilustrações, isto, pelo fato da população em geral não ser alfabetizada cientificamente (BUENO, 2010). Brockington e Mesquita (2016) ressaltam que, para o entendimento dos conceitos neurocientíficos, tal como é o objetivo das atividades propostas neste estudo, se faz necessário o uso de uma linguagem adaptada e não somente simplificada, para que as açóes, com sua finalidade de divulgar conceitos importantes da neurociência, não acabem gerando efeitos opostos, disseminando os conhecidos neuromitos. A escolha dos materiais também é algo importante, e verificamos o grande interesse da população pelas peças anatômicas e fôlderes utilizados. De Paula (2012) ressalta que o propósito da utilização de materiais como fôlderes é transmitir rapidamente ideias sem cansar os leitores, de forma objetiva e ilustrativa, similarmente ao que foi realizado durante as açóes.

Vargas et al. (2013) concluiu que a não popularização da neurociência não está relacionada à falta de interesse da população, mas sim, ao fato de haver poucas oportunidades de divulgação científica encontradas dentro da comunidade. Dessa forma, essas iniciativas têm se mostrado de fundamental importância, pois o entendimento da ciência vai permitir que a população compreenda melhor o mundo em que vive, e consequentemente, possibilitar a aplicabilidade do saber científico em seu dia-a-dia e na preservação de sua saúde. No caso dos temas aqui trabalhados, por exemplo, a população pôde compreender a importância da prática de exercícios físicos para o bom funcionamento do cérebro, o valor de uma boa alimentação para a saúde do SNC, a influência de uma boa noite de sono para a consolidação da memória etc., estando, agora, apta a exercer esses bons hábitos condizentes com o bem-estar do cérebro em sua rotina diária.

A ideia de organizar as atividades foi prazerosa, mas ao mesmo tempo desafiadora para o grupo proponente, pois alguns eventos tratavam-se 
das primeiras açóes públicas de novos integrantes do POPNEURO 2016, visto que, apesar do programa ter iniciado em 2013, a cada ano costuma haver uma renovação da maior parte da equipe. Levando isso em conta, náo apenas o público geral foi beneficiado, recebendo novas informaçóes por meio das explanaçóes teóricas, como também os acadêmicos envolvidos que, ao discutir conhecimentos, tiveram oportunidade de trabalhar com sua capacidade oratória, tornando-se, gradativamente, mais desinibidos e confiantes para apresentaçôes, além de participarem do processo dialógico do conhecimento. Segundo Reis (1998), uma das maiores recompensas do trabalho de divulgador cientifico é aprender, tentando ensinar. Dessa forma, tudo indica que jovens acadêmicos que também trabalham divulgando a ciência terão muitas vantagens nos contextos de comunicação e sociabilidade, além da continuidade sobre assuntos táo recorrentes nas graduaçóes das ciências da saúde, área de estudo de todos os discentes participantes do POPNEURO.

Ainda, em diversos eventos em que o grupo compareceu, estiveram presentes diversos profissionais da saúde, como odontólogos, fisioterapeutas, residentes do hospital, com a finalidade de proporcionar a comunidade em geral atendimentos e informaçóes variadas. Neste sentido, Ribeiro (2005) afirma que a experiência em equipe multidisciplinar e a possibilidade da interdisciplinaridade é outro aspecto que não é estudado durante a graduação, logo, os acadêmicos do POPNEURO, por meio dos eventos e açôes de extensão, tiveram a oportunidade de vivenciar o atendimento à comunidade junto com outros profissionais, interagindo com outras profissóes.

\section{CONSIDERAÇÕES FINAIS}

Os resultados obtidos demonstram que atividades de divulgaçáo da Neurociência, como as descritas e realizadas em Uruguaiana-RS ano de 2016, são efetivas para popularizar conceitos científicos, fazendo-o de uma maneira agradável e lúdica e permitindo uma aproximação dos participantes com a Neurociência. Além disso, atividades como as realizadas também contribuem para a formaçáo dos discentes envolvidos, ampliando suas oportunidades de formaçáo acadêmica e contato com a comunidade. 


\section{REFERÊNCIAS}

BORGES, J. L.; CARNIELLI, B. L. Educação e estratificação social no acesso à universidade pública. Cadernos de Pesquisa, São Paulo, v. 35, p. 113-139, jan.-abr. 2005. doi: https://doi.org/10.1590/S010015742005000100007.

BROCKINGTON, G.; MESQUITA, L. As consequências da má divulgação científica. Revista da Biologia, São Paulo, v. 15, p. 29-34, jan. 2016. doi: https://doi.org/10.7594/revbio.15.01.03.

BUENO, O. F. A.; EKUnI, R.; ZEGGIO, L. Caçadores de neurônios: o que você sabe sobre seu cérebro é verdade? São Paulo: Memnon, 2015. 197 p.

BUENO, W. C. Comunicação científica e divulgação científica: aproximaçôes e rupturas conceituais. Informaçáa \& Informaçáa, Londrina, v. 15, p. 1-12, 2010. doi: https://doi.org/10.5433/19818920.2010v15n1espp1.

DE PAULA, F. A. Fôlder ambiental: um suporte educativo à divulgação científica focado na conservação da biodiversidade. 2012. $61 \mathrm{f}$. Trabalho de Conclusão de Curso (Graduação em Ciências Biológicas) - Universidade Federal do Rio Grande do Sul, Porto Alegre, 2012.

DEKKER, S. et al. Neuromyths in education: prevalence and predictors of misconceptions among teachers. Frontiers in Psychology, Brussels, v. 3, p. 429, Oct. 2012. https://doi.org/10.3389/fpsyg.2012.00429.

FILIPIN, G. et al. POPNEURO: relato de um programa de extensão que busca divulgar e popularizar a neurociência junto a escolares. Revista Brasileira de Extensáo Universitária, Chapecó, v. 6, n. 2, p. 87-95, 2015. doi: https://doi.org/10.1523/ JNEUROSCI.0005-08.2008.

FRIEDMAN, D. P. Public outreach: a scientific imperative. The Journal of Neuroscience, Washington, v. 28, p. 11743-11745, Nov. 2008. doi: 10.1523/JNEUROSCI.0005-08.2008.

GIL, A. C.; OLIVA, E. C.; GASPAR, M. A. A regionalidade como área de estudo da administração: um estudo de caso de um programa 
de mestrado em administração. Revista Gestáo.Org, Recife, v. 1, p. 11-24, nov. 2008. Disponível em: <http://repositorio.uscs.edu. br/bitstream/123456789/99/2/Regionalidade.pdf>. Acesso em: 20 jun. 2017.

HACKNEY, S. The University and its Community: past and present. The Annals of the American Academy of Political and Social Science, Pensilvania, v. 488, p. 135-147, Nov. 1986.

HERNANDO, M. C. et al. Divulgação científica: um grande desafio para este século. Ciência e Cultura, São Paulo, v. 57, p. 18-20, abr.jun. 2005. Disponível em: < http://cienciaecultura.bvs.br/pdf/cic/ v57n2/a13v57n2.pdf>. Acesso em: 15 jul. 2017.

HOFF, D. N.; SAN MARTIN, A. S.; SOPEÑA, M. B. Universidades e desenvolvimento regional: impactos quantitativos da Unipampa em Sant'ana do Livramento. Redes: Revista do Desenvolvimento Regional, Santa Cruz do Sul, v. 16, p. 157-183, set.-dez. 2011. doi:10.17058/redes.v16i3.1699.

ILLES, J. et al. NeuroTalk: improving the communication of neuroscience research. Nature Reviews: Neuroscience, Basingstoke, v. 11, p. 61-69, Jan. 2010. doi: https://doi.org/10.1038/nrn2773.

JEZINE, E. As práticas curriculares e a extensão universitária. In: CONGRESSO BRASILEIRO DE EXTENSÃO UNIVERSITÁRIA, 2., 2004, Belo Horizonte. Anais... Belo Horizonte, 2004. Disponível em: <http://br.monografias.com/trabalhos-pdf901/as-practicascurriculares/as-practicas-curriculares.pdf>. Acesso em: 6 maio 2017.

MARANDINO, M. Transposição ou recontextualização? Sobre a produção de saberes na educação em museus de ciências. Revista Brasileira de Educaçáo, Rio de Janeiro, v. 26, p. 95-108, maio-ago. 2004. doi: https://doi.org/10.1590/S1413-24782004000200008.

MARCHIORO, D. F. et al. A Unipampa no contexto atual da educação superior. Avaliação [online], Campinas, v. 12, n. 4, p. 703-717, dez. 2007. doi: https://doi.org/10.1590/S1414-40772007000400008.

MARTINS, A.; MELLO-CARPES, P. B. A proposal for undergraduate students' inclusion in brain awareness week: promoting interest in curricular neuroscience components. The Journal of Undergraduate 
Neuroscience Education, Berlin, v. 13, p. 41-44, Oct. 2014.

NASCIMENTO JÚNIOR, A. F.; SOUZA, D. C. O fazer artístico na popularização do conhecimento biológico: relato de experiências. REMEA, Rio Grande. v. 23, p. 71-87, jul.-dez. 2009. Disponível em: <https://www.seer.furg.br/remea/article/view/3956>. Acesso em: 15 maio 2017.

PASQUINELLI, E. Neuromyths: why do they exist and persist? Mind, brain, and education, Hoboken, v. 6, p. 89-96, May 2012. doi: https://doi.org/10.1111/j.1751-228X.2012.01141.x.

PETERS, H. P. et al. Science-media interface it's time to reconsider. Science Communication, v. 30, p. 266-276, Sept. 2008. Disponível em: <http://journals.sagepub.com/doi/ abs/10.1177/1075547008324809>. Acesso em: 20 maio 2017.

POLIAKOFF, E.; WEBB, T. L. What factors predict scientists' intentions to participate in public engagement of science activities? Science Communication, v. 29, p. 242-263, Dec. 2007. Disponível em: <http://journals.sagepub.com/doi/ abs/10.1177/1075547007308009>. Acesso em 12 abr. 2017.

REIS, J. Ponto de Vista. In: Cientistas do Brasil: depoimentos. São Paulo: SBPC, 1998. p. 3-7.

RIBEIRO, K. S. Q. S. A contribuição da extensão comunitária para a formação acadêmica em fisioterapia. Fisioterapia e Pesquisa, São Paulo, v. 12, p. 22-29, abr. 2005. Disponível em: <https://www. revistas.usp.br/fpusp/article/view/76622/80394>. Acesso em: 10 abr. 2017.

RYKUN, A.Y.; YUZHANIONOV, K. M.; VYCHUZHANINA, E. $\mathrm{V}$. Universities and local communities: problems and perspectives of interaction. Procedia: Social and Behavioral Sciences, Amsterdam, v. 200, p. 359-365, Aug. 2015. doi: https://doi.org/10.1016/j. sbspro.2015.08.078.

THIOLLENT, M. J. M. Construção do conhecimento e metodologia da extensão. In: CONGRESSO BRASILEIRO DE EXTENSÃO UNIVERSITÁRIA, 1., 2002, João Pessoa. Anais... João Pessoa, 2002. Disponível em: <http://www.prac.ufpb.br/anais/Icbeu_anais/anais/ 
saude/saude.html>. Acesso em: 12 abr. 2017.

VARGAS, L. et al. Conhecendo o sistema nervoso: açóes de divulgação e popularização da neurociência junto a estudantes da rede pública de educaçáo básica. Ciências \& Cogniçáo, Rio de Janeiro, v. 19, n. 2, p. 233-241, 2013. Disponível em: <http://www.cienciasecognicao. org/revista/index.php/cec/article/view/910>. Acesso 12 abr. 2017.

VASCONCELOS, E. M. Educação popular: de uma prática alternativa a uma estratégia de gestão participativa das políticas de saúde. Physis [online], Rio de Janeiro, v. 14, p. 67-83, jan. 2004. doi: https://doi.org/10.1590/S0103-73312004000100005.

Submetido em 17 de julho de 2017.

Aprovado em 31 de outubro de 2017. 